\title{
POPULATION AGING AND ITS ECONOMIC CONSEQUENCES FOR THE PEOPLE'S REPUBLIC OF CHINA
}

\author{
Ronald Lee
}

NO. 17 
ADB East Asia Working Paper Series

\section{Population Aging and Its Economic Consequences for the People's Republic of China}

Ronald Lee

No. 17 | November 2019
Professor, Graduate School, Departments of Demography and Economics, University of California at Berkeley. This paper was prepared as a background paper to the preparation of the High-Level Round Table Discussion on the People's Republic of China's transition to high-quality development, coordinated by the Asian Development Bank. The author thanks the researchers whose work was drawn upon, especially Wang Feng, Yong Cai, and Shen Ke for use of their National Transfer Accounts Project data for the People's Republic of China; and Warren Sanderson, Wolfgang Lutz, K. C. Samir, Josh Goldstein, Yi Zeng, and John Strauss for data and helpful discussions. Suggestions from Benedict Bingham improved the paper in many ways. 
(C) 2019 Asian Development Bank

6 ADB Avenue, Mandaluyong City, 1550 Metro Manila, Philippines

Tel +632 8632 4444; Fax +63286362444

www.adb.org

Some rights reserved. Published in 2019.

Printed in the Philippines

Publication Stock No. WPS190577-2

DOI: http://dx.doi.org/10.22617/WPS190577-2

The views expressed in this publication are those of the authors and do not necessarily reflect the views and policies of the Asian Development Bank (ADB) or its Board of Governors or the governments they represent.

ADB does not guarantee the accuracy of the data included in this publication and accepts no responsibility for any consequence of their use. The mention of specific companies or products of manufacturers does not imply that they are endorsed or recommended by ADB in preference to others of a similar nature that are not mentioned.

By making any designation of or reference to a particular territory or geographic area, or by using the term "country" in this document, $A D B$ does not intend to make any judgments as to the legal or other status of any territory or area.

This work is available under the Creative Commons Attribution 3.0 IGO license (CC BY 3.0 IGO)

https://creativecommons.org/licenses/by/3.0/igo/. By using the content of this publication, you agree to be bound by the terms of this license. For attribution, translations, adaptations, and permissions, please read the provisions and terms of use at https://www.adb.org/terms-use\#openaccess.

This CC license does not apply to non-ADB copyright materials in this publication. If the material is attributed to another source, please contact the copyright owner or publisher of that source for permission to reproduce it. $A D B$ cannot be held liable for any claims that arise as a result of your use of the material.

Please contact pubsmarketing@adb.org if you have questions or comments with respect to content, or if you wish to obtain copyright permission for your intended use that does not fall within these terms, or for permission to use the ADB logo.

Corrigenda to ADB publications may be found at http://www.adb.org/publications/corrigenda.

Notes:

In this publication, “\$” refers to United States dollars.

ADB recognizes "China” as the People's Republic of China.

The ADB East Asia Working Paper Series is a forum for stimulating discussion and eliciting feedback on ongoing and recently completed research and policy studies undertaken by the East Asia Department of the Asian Development Bank (ADB) staff, consultants, or resource persons. The series deals with key economic and development problems, as well as conceptual, analytical, or methodological issues relating to project/program economic analysis, and statistical data and measurement. The series aims to enhance the knowledge on Asia's development and policy challenges; strengthen analytical rigor and quality of ADB's country partnership strategies, and its subregional and country operations; and improve the quality and availability of statistical data and development indicators for monitoring development effectiveness.

The ADB East Asia Working Paper Series is a quick-disseminating, informal publication whose titles could subsequently be revised for publication as articles in professional journals or chapters in books. The series is maintained by the East Asia Department.

This paper was prepared as a background study for the preparation of the High-Level Round Table Discussion on the People's Republic of China's transition to high-quality development, coordinated by the Asian Development Bank. 


\section{CONTENTS}

FIGURES iv

ABSTRACT

ABBREVIATIONS vi vi vi vis

$\begin{array}{lll}\text { I. } & \text { INTRODUCTION } & 1\end{array}$

II. POPULATION AGING 2

A. Proximate Causes

B. The Fertility Situation $\quad 5$

C. The Fertility Decline since 1970 and the Role of Fertility Policy in that Decline 7

D. Is Population Aging about Chronological Age or Physiological Age 9 and Functional Abilities?

E. Trends in Health and Disability of the Older Population 9

F. Estimating Change in the Potential Workforce as the Population Ages 10

III. ECONOMIC CONSEQUENCES OF POPULATION AGING 11

A. Age Patterns of Labor Income and Consumption 11

B. Population Aging and the Support Ratio 13

C. How Actual Age Patterns of Labor Income and Consumption Change the Support Ratio 14

D. The Second Demographic Dividend $\quad 14$

E. Is Fertility Too Low?

F. Population Aging and the Long-Term Fiscal Outlook for Social Welfare Spending 16

G. Policies to Raise Fertility Elsewhere that Have Worked and Not Worked 17

$\begin{array}{llr}\text { IV. } & \text { POLICY RECOMMENDATIONS } & 18\end{array}$

A. Fertility Policy 18

B. Pension Policy 18

C. Education and Health Policy 20

$\begin{array}{lr}\text { V. CONCLUSIONS } & 20\end{array}$

$\begin{array}{lr}\text { REFERENCES } & 22\end{array}$ 


\section{FIGURES}

1 Eventual Steady State Old-Age Dependency Ratio Corresponding to Life Expectancy and Total Fertility Rate, 1950, 2015, and 2100 Projections

2 Old-Age Dependency Ratio Using the United Nations' Medium- and Low-Fertility Variants, and the Wittgenstein Centre's Medium Scenario

3 Fertility Estimates and Projections, 1950-2100 6

4 Projections of Women's Educational Attainment and Its Relation to Their Fertility 8

5 National Transfer Accounts Age Profiles for Labor Income and Consumption, 2002-2014 12

6 Demographic and Weighted Support Ratios, 1950-2100 


\begin{abstract}
Population aging in the People's Republic of China (PRC) is mainly due to rapid fertility decline after 1970, a third of which was due to government policy, and the balance to social and economic development. Relaxing fertility policies now would probably not have a large effect on fertility, and rising educational attainment may reduce future fertility by 0.3 births per woman. The successes and failures of European fertility policies can guide policy. In any case, the PRC's population will age rapidly, with the old-age dependency ratio (OADR) more than tripling by 2065. This will cause severe fiscal problems for current old-age programs, particularly for pensions. The general economic impact will be less severe, as partially offset by rising education and increased capital per worker. Focusing on a particular age, like 65, is a mistake. Health, cognition, and vitality are more important than age itself and these will improve due to past increases in education and better living conditions for children. The retirement age should be raised. One good approach is building automatic adjustment mechanisms into old-age programs like pensions. For example, retirement age, taxes, and benefits can be linked to life expectancy and to the OADR as in some European countries. This would increase the work effort of the elderly and avoid recurring political problems in the future.
\end{abstract}




\title{
ABBREVIATIONS
}

\author{
ADL activities of daily living \\ OADR old-age dependency ratio \\ NDC nonfinancial defined contribution or notional defined contribution \\ NTA National Transfer Accounts \\ PRC People's Republic of China \\ TFR total fertility rate
}




\section{INTRODUCTION}

The United Nations (UN 2019) projects that the old-age dependency ratio will more than triple between 2020 and 2065 in the People's Republic of China (PRC). Under current program structures, this aging would cause severe fiscal problems, particularly for pensions. This paper argues that the impact for the general economy will be less severe, because the effect of the population's chronological aging should be offset by growth in labor productivity due to the increased education of the workforce and the impact of the "second demographic dividend" on investment in physical capital. Also, consumption levels are similar across adult ages while public expenditures on adults are heaviest at old ages.

To substantiate its thesis, the paper examines the causes of population aging and its impact on economic growth in the PRC. It makes three key points. First, population aging in the PRC today is mainly due to the rapid decline in fertility after 1970 . While this decline partly reflects the impact of government policy-recent causal analyses estimate that about a quarter to a third of the decline in the fertility rate from over 6.00 to about 1.60 was due to government policy-it mainly reflects the same social and economic development drivers that caused the decline in fertility in other East Asian countries. One implication of this is that relaxing family planning policy now may not reverse the trajectory of fertility in the PRC. Indeed, the rapid rise in educational attainment may reduce fertility further, by about 0.3 births per woman, in coming decades. The paper argues that if the fertility rate stays at its currently estimated level of about 1.60, it should not be too problematic. But if the fertility rate continues to fall, or if it turns out to be much lower than currently estimated, then a more proactive approach to raising fertility rates may become more urgent. Under these scenarios, a narrow focus on financial incentives may not be enough, and the government may wish to look at the successes and failures of family and fertility policies in Europe, as these could provide useful lessons for a broader policy framework to address the decline in fertility rates.

Government policy should not focus excessively on the proportion of the population older than some particular age. Only policies and culture make an arbitrary age like 55 or 65 matter. What really matters are the health, strength, cognition, vitality, and freedom from disability of the population (Sanderson and Scherbov 2010). This paper argues that the health and vigor of the elderly will improve in the coming decades due to rising educational attainment and improved early childhood development of subsequent generations of elderly arising from growing up in much better conditions. The rise in the proportion of the population unable to work and needing care is expected to be much less than the rise in the proportion of the population aged 65 and over. This is the essence of the saying that "70 will be the new 60." However, in the absence of changes in the current structure of public programs, population aging will cause severe fiscal problems. Specifically, standard projections suggest that if the age profile of per capita social welfare spending (education, health, pensions) relative to gross domestic product (GDP) per capita stays unchanged, then total social spending will rise from 10\% of GDP in 2014 to 15\% in 2030, and $30 \%$ in 2060, solely due to population aging. 'If per capita benefit levels rise relative to GDP per capita toward averages as seen in countries of the Organisation for Economic Co-operation and Development (OECD), social spending will reach $40 \%$ of GDP by 2060 , which is clearly unsustainable (Cai, Wang, and Shen 2018). The bulk of this increase is in the pension program; however, the familial support system will also come under pressure as the population ages. Taking into account private transfers to children and to the elderly, the increase in private transfers will be about half as great as it is for total public transfers. The paper therefore argues that it will be important to incorporate automatic adjustment mechanisms into old-age programs, so that future adjustments are anticipated well in advance of them taking effect. As can be seen from the experience in Europe and the United States (US), it is politically difficult and costly

Here per capita GDP is measured per working-age person, not per total population. 
to raise the retirement age since workers will feel that something owed to them is being taken away. The political cost is much lower if workers early in their working lives realize there will be future adjustments, and expect and plan for them. The Swedish and German pension systems provide useful examples of how automatic adjustments can be transparently built into pension systems to act as stabilizers-for example, by linking the retirement age and benefits to life expectancy, and adjusting benefit and tax rates as the ratio of retirees to workers changes.

\section{POPULATION AGING}

\section{A. Proximate Causes}

A useful starting point for an analysis of population aging in the PRC is the concept of a stable population, which would arise if age-specific fertility and mortality were to remain constant over a century or more. In this hypothetical case, the share of the population at each age would converge to a so-called stable age distribution. This age distribution depends only on fertility and mortality, independent of the starting population age distribution. Stable populations permit the investigation of the causes of population aging in an abstract context, which is the starting point here.

A standard measure for populating aging is the old-age dependency ratio (OADR) - the ratio of the population ages 65 and over to the population at ages 20-64. Each fixed level of fertility and mortality corresponds to a specific level of the OADR in a stable population. Figure 1 shows a contour map for the OADR in relation to the total fertility rate (TFR) and life expectancy at birth. The TFR varies from 1 to 7 births per woman, and life expectancy from 20 years to 90 years (for men and women).

Figure 1 shows that for the range of life expectancies from 20 to about 70 years, the contours are quite flat. See, for example, the contour line labeled 0.10, on which lies the point corresponding to a life expectancy of 20 and a TFR of 4.5. However, the same TFR but with a life expectancy of 60 or 70 is also on that line. This shows that large differences in life expectancy barely change the OADR in that range. By contrast, if life expectancy is 60 years and the TFR is varied from 5.5 to 1.5 births per woman, many contours are crossed, with the OADR rising from 0.08 to 0.35 .

This example illustrates that fertility change has a powerful effect on the OADR when life expectancy is below about 70. When life expectancy is above 70, the contour lines sweep upward more steeply. Here, mortality level matters much more for the OADR and for population aging in general. This is because when mortality declines from a high level, infant and child mortality drop sharply, and more births survive to adulthood. The effect is similar to the effect of higher fertility, making the population grow faster. A faster growing population has many more young people than old people. In this way lower mortality and higher life expectancy tend to make the population younger, contrary to what might be expected. But if people live longer, that also works in the opposite direction, tending to make the population older. When life expectancy is below about 70 years, the two effects roughly cancel out-and mortality differences have little effect. But starting at a higher level of life expectancy almost all children survive in any case, so further mortality declines no longer raise growth rates and make the population younger. Here, the second effect dominates and the OADR rises, because people are living longer.

Turning to the specific situation in the PRC, the red dot in Figure 1 labeled 1950 shows the level of fertility and life expectancy from 1950 to 1954 (about 6 births per woman and 44 years), and the OADR level that would correspond in the long term (about 0.068). According to UN data, the actual OADR in 1950 


\section{Figure 1: Eventual Steady State Old-Age Dependency Ratio Corresponding to Life Expectancy and Total Fertility Rate, 1950, 2015, and 2100 Projections}

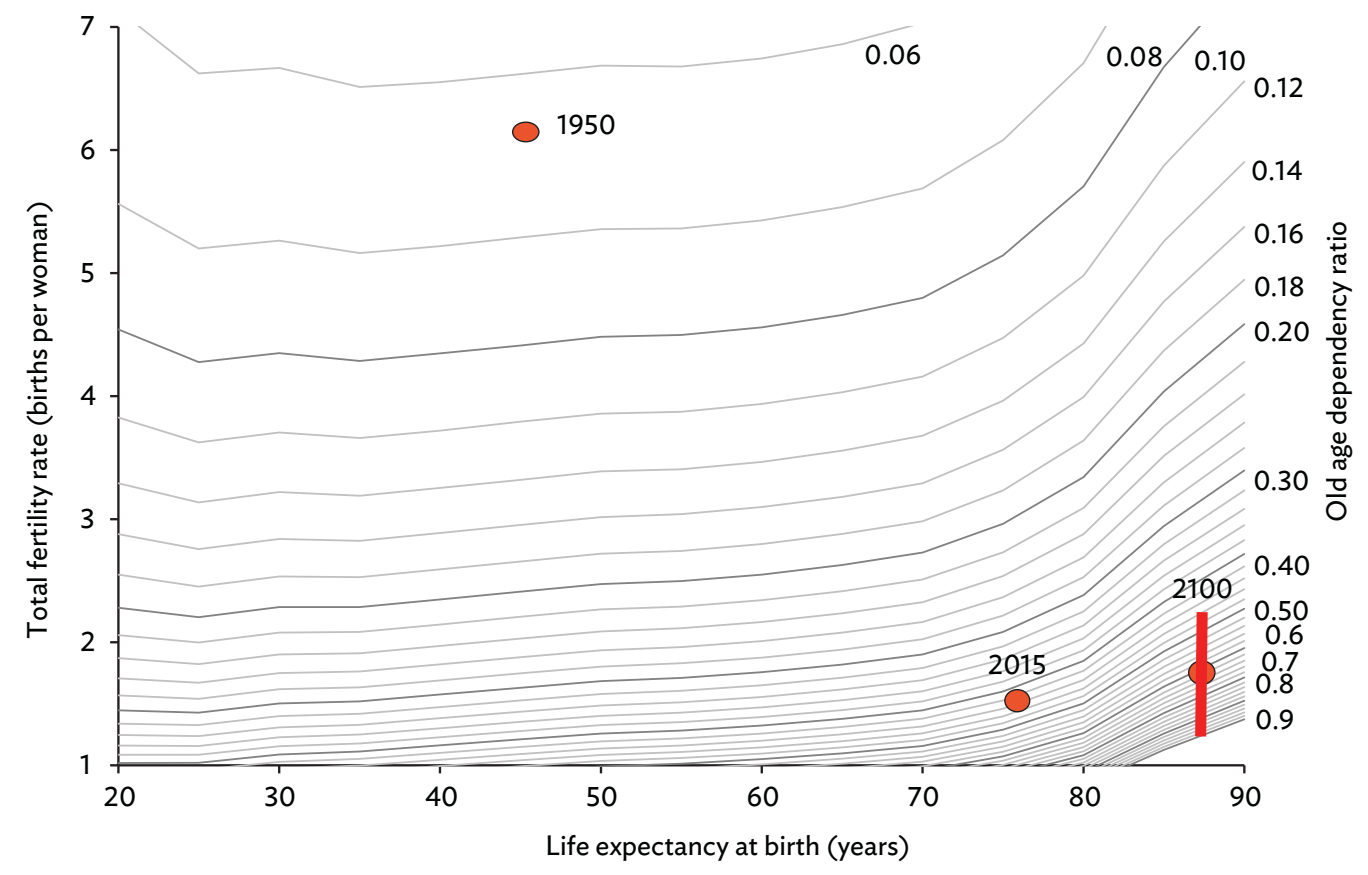

Notes:

1. The dots for 1950,2015 , and the 2100 projection show life expectancy and the total fertility rate.

2. The bar for 2100 indicates the high-low range for projected fertility in that year. For 2100 , the range is 0.5 births per woman greater or smaller than the medium variant.

3. The contours indicate the level of the old-age dependency ratio in the long term, rather than immediately.

Sources: Based on Coale and Demeny (1982); values for the People's Republic of China from United Nations (2017).

was higher, at 0.085 , reflecting different fertility and mortality in the past. The contour value shows only what would happen in the long term if the rates for 1950 remained constant indefinitely.

The dot labeled 2015 shows the TFR and life expectancy during 2015-2019 (1.6 births and 76.5 years) and the OADR (about 0.40), which is almost six times higher than for the 1950 rate. The PRC's actual OADR for 2015-2019 is 0.165, according to the UN, or less than half of its eventual stable value of 0.40 if fertility and mortality were to remain at these levels. The dot labeled 2100 shows the UN projections for that year (TFR of 1.8 births and life expectancy of 87.4 years), with the stable OADR about 0.6, and the bar shows the low-to-high fertility range the UN assigns for its projections, from 1.3 to 2.3 births per woman, with the OADR ranging from 0.90 to 0.45 . $^{2}$ The projected OADR for 2100 is 0.64 , very close to the stable value shown in Figure 1. Note that the OADR would be twice as high if the TFR were 1.3 births per woman, as it would be if it were 2.3.

2 The UN does not give high-low ranges for its mortality projections. 
Figure 1 clearly shows the main cause of population aging between the demographic regimes of 1950 and 2015 is low fertility, not low mortality. But this gives the outcome across stable populations, not in real time. Because it takes about a century for a population to move to a new steady state after fertility or mortality changes, transitions between steady states need to be considered. For transitional paths it is useful to simulate changes in population aging through projection-type exercises. For this purpose, UN projections can be used. But questions of interpretation still remain. If fertility is already very low, as it is in the PRC, but no longer declining further, can it be held that fertility is not responsible for further population aging? Even with no further changes in fertility or mortality, the OADR would more than double in the future as the population moves toward its new stable age distribution, and this doubling is due to the fertility decline many decades earlier. Fertility and its changes or lack of changes is still the dominant cause of population aging in the PRC and globally. But if the PRC's current TFR of about 1.6 is a given, and the question is posed as to whether future changes in fertility or in mortality are more likely to drive future population aging, then the probable answer would be that mortality change will be more important. This is because life expectancy is expected to keep rising, while fertility may not change much or may even rise a bit.

Despite a lively debate on this issue (Preston and Stokes 2012; Lee and Yi 2017; Murphy 2017), it is safe to conclude that fertility is the main lever through which the government might affect population aging, and that the future trajectory of fertility will have a crucial impact on the extent and pace of population aging in the PRC. UN projections show how this would play out in real time, as opposed to the abstract space of stable populations. Under the UN's medium variant, the TFR will rise from 1.60 to 1.80 and then plateau at that level. That would reduce the OADR in 2100 from 0.755 if fertility remains at 1.60, to 0.641 if fertility rises to 1.80, as the UN assumes. But if fertility was instead to rise to the replacement level of 2.1, then the OADR would be about 0.540 . Under the UN's high fertility (TFR $=2.3$ ) and low fertility $(T F R=1.3)$ variants, the OADR would be 0.477 for high fertility, and 0.945 for low fertility, differing by a factor of two. This would be similar to the stable-population result shown in Figure 1. A low TFR of 1.3 would mean about one adult younger than 65, per older person aged 65 and above.

Figure 2 shows some of these possibilities. The contrast between the UN's medium and low fertility variants shows that the different fertility levels will have a powerful effect on the OADR in 2100. But fertility levels have virtually no effect on the OADR until after 2040, because those born after 2020 will not turn 20 until after 2040. In fact, the effect on the OADR of these fertility differences does not really begin to become important until after 2050.

The Wittgenstein Centre for Demography and Global Human Capital in Austria produces its own set of international population projections that use a different approach than the UN (European Commission 2018). Its medium-fertility OADR projection for the PRC for 2100 is similar to the UN's low fertility projection (Figure 2). The Wittgenstein Centre's low fertility projection-assuming a high rate of economic development and therefore more rapid educational progress and lower fertility-gives an extremely high OADR of 1.5 in 2100.

It is possible to see what would happen if there were no further improvements in life expectancy over the course of the century after 2017 by viewing the UN's "constant mortality" projection variant, in which fertility follows the medium assumption rising to 1.80 . With no further mortality improvements, the OADR in 2100 would be 0.39 rather than 0.64 under the medium scenario. This comparison isolates the considerable effect of the projected rise in life expectancy. 
Figure 2: Old-Age Dependency Ratio Using the United Nations' Medium- and Low-Fertility Variants, and the Wittgenstein Centre's Medium Scenario

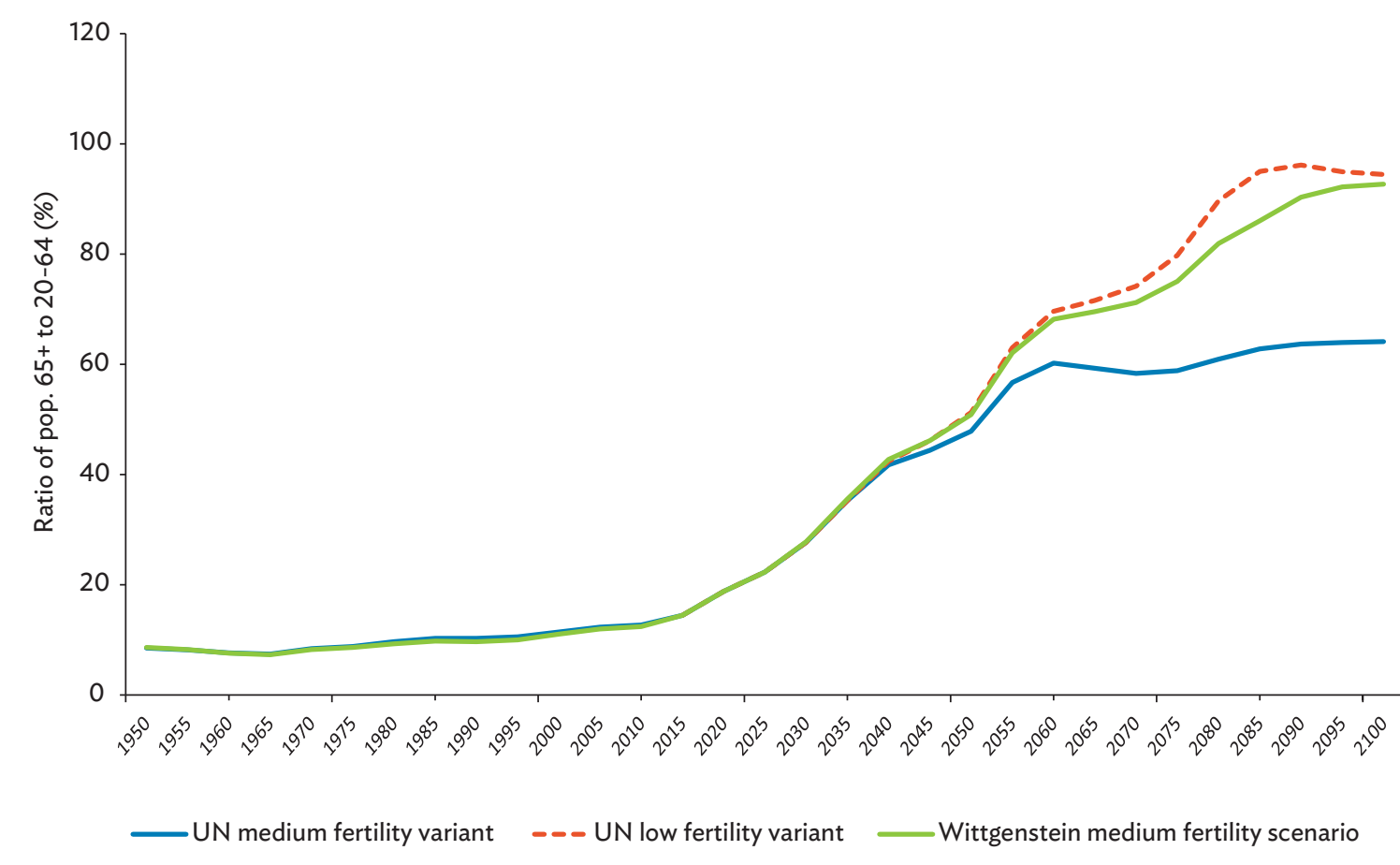

UN = United Nations.

Notes: By 2100 , the old-age dependency ratio would be $50 \%$ higher under a low fertility variant as under the medium fertility one, a difference of only 0.5 births in the total fertility rate projection. But until 2050 , fertility makes very little difference to the old-age dependency ratio. Therefore, fertility trends will make a very big difference over the course of the century, but there is a long lag time before they matter much.

Sources: UN (2017) and European Commission (2018).

\section{B. The Fertility Situation}

The most commonly used measure of fertility is the "period" TFR, which is the sum across all ages of women's birth rates in a given year or period. The UN (2017) estimated the PRC's period TFR during 2010-2014 at 1.60 births per woman, and projected it to be 1.63 for 2015-2019. The UN's estimate is at the high end of the range of estimates in the literature, which include the following leading examples.

(i) The Wittgenstein Centre makes projections based on surveys of opinions of a group of experts, and its 2018 projection assumes a period TFR in 2015 of 1.47, somewhat lower than the UN (European Commission 2018).

(ii) Some other low estimates are based on the 2015 1\% Population Sample Survey, including an estimate of just over 1.05 in the China Statistical Yearbook 2016. Guo, Gietel-Baten, and Gu (2018), using the same survey, estimated just under 1.05.

(iii) Jiang et al. (2017), in contrast, in a careful studyderive adjustment factors through analysis of the 2010 micro census, leading to a fertility estimate very close to 1.52 during 2005-2009, and close to 1.50 from 2010 to 2014. In a personal communication, the corresponding author of that paper states that new evidence indicates that the TFR in recent years has been between 1.50 and 1.60 . 
Despite some uncertainty, the UN TFR estimate of 1.60 is broadly consistent with the strongest studies. Some of these fertility estimates and projections are shown in Figure 3, including the UN (2017) medium and low fertility variants. The UN low fertility variant is quite close to the Wittgenstein Centre projection.

Figure 3: Fertility Estimates and Projections, 1950-2100

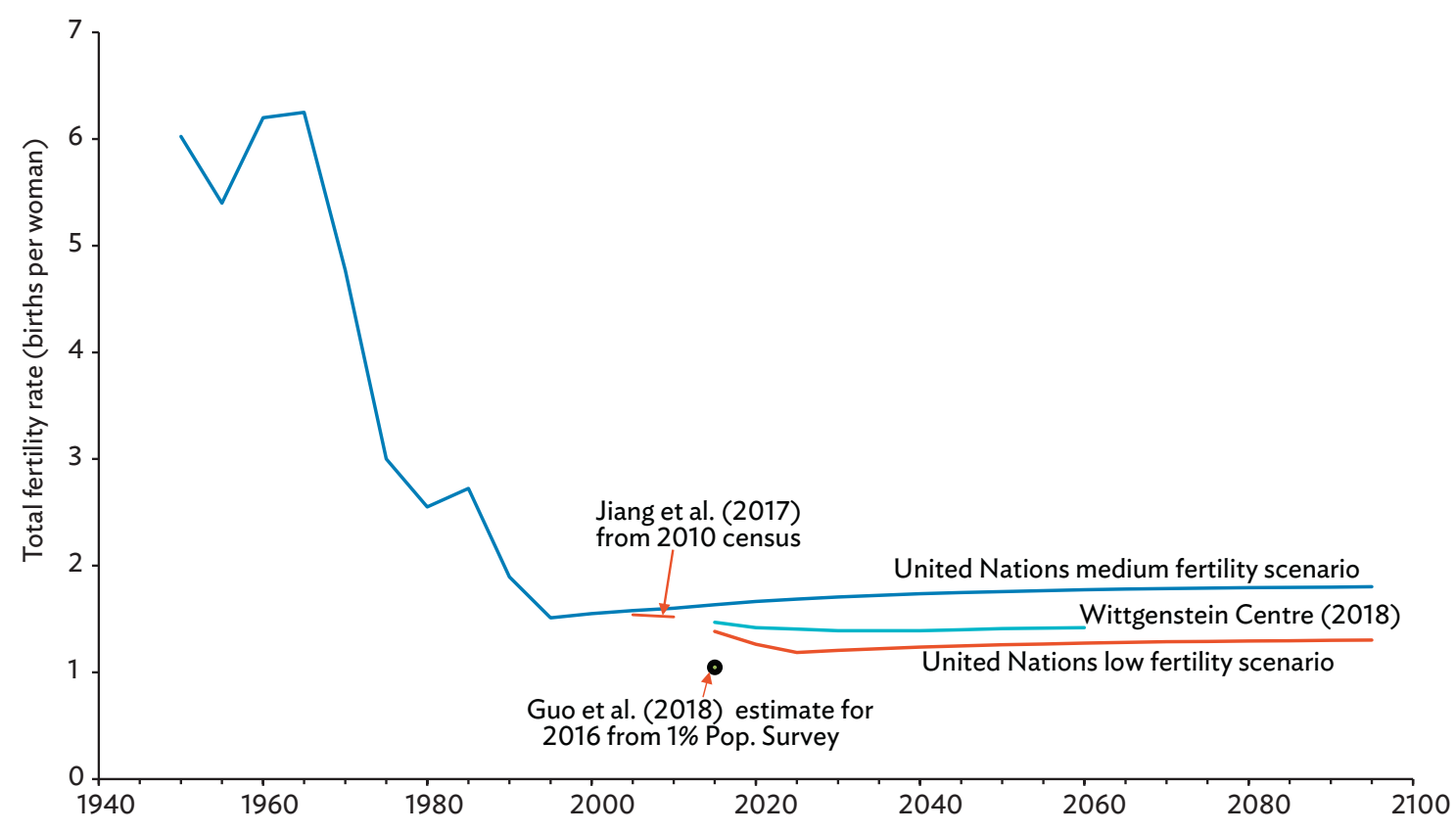

Note: For United Nations, date at start of 5-year interval, otherwise for year.

Note: United Nations data at start of 5-year interval, otherwise for year.

Sources: Guo, Gietel-Basten, and Gu (2018).

Although the period TFR is calculated from the age-specific birth rates in a given calendar year, it is nonetheless often interpreted as the number of births a woman would have over her lifetime. This interpretation makes sense when age-specific rates are stable over time, but if women tend to postpone giving birth in a particular year, the period TFR for that year will be reduced below its normal level, giving a distorted view of the typical number of lifetime births. So, if the average age of having a first birth rises over time (reflecting postponement of childbearing), that will artificially depress the period TFR. This is known as a "tempo" effect, arising from a change in the timing of births. In this case, a low period TFR is of less concern.

In the PRC, it appears that the mean age at first birth rose from about 26.0 years in 2005 to about 28.5 in 2015, based on data from multiple surveys and published estimates summarized in the Human Fertility Collection. ${ }^{3}$ As a conservative estimate, it can be supposed there was a rise of 0.2 years of age

3 The Human Fertility Collection is a joint project of the Max Planck Institute for Demographic Research and the Vienna Institute of Demography, which collates various international fertility data to supplement the Human Fertility Database. (See Human Fertility Collection. China. https://www.fertilitydata.org/cgi-bin/country.php? code=CHN for data on the PRC.) 
each calendar year over this period (a bit below 2.5/10 =.25). An approximate adjustment can then be made by multiplying the period TFR by $1 /(1.0-0.2)=1 / .8=1.25$. For example, if the true period TFR in 2015 was 1.50, as reported in Jiang et al. (2017), then the estimate of completed lifetime fertility for women bearing children in that year would be $1.25^{\star} 1.50=1.875$, or roughly 1.9. By this argument, women bearing children today may end up with 1.9 rather than 1.5 births. But it is inherently unclear to which generations of women this estimate applies. What is clear is that when the mean age at first birth stops rising, there will no longer be a distorting influence on the period TFR. The observed rate should then rise toward the underlying level of completed cohort fertility (or the "cohort" TFR), whatever that may be. If the trend in the mean age at first birth reverses and begins to decline, then there would be an upward distortion in the period TFR. The point here is that the level of the TFR in recent years may have been artificially depressed by this "tempo" factor, and the underlying level of lifetime fertility may actually be somewhat higher.

Some studies have estimated the completed lifetime fertility of specific birth cohorts of women in the PRC. For the study by Goldstein, Myrskylä, and Cheng (2013:18), these results, while undeniably subject to large uncertainty, suggest that cohort fertility declined sharply until the 1970s cohorts, but then stabilized to a level of approximately 1.7 children per woman. These results are consistent with Morgan, Zhigang, and Hayford (2009) who find that a reasonable range for mean completed fertility of women born after 1970 is 1.6 to 1.7. Jiang et al. (2017) used the 2010 micro census to estimate the completed fertility at age 49 of women born annually from 1962 to 1970, and for those born in 1975 (who were 35 at the time of the census and hence require some projection). They found that completed cohort fertility dropped regularly in this period, from 2.0 for those born in 1962 to 1.5 for those born in 1975, and thus a little lower than the estimates of Goldstein Myrskylä, and Cheng (2013) and Morgan, Zhigang, and Hayford (2009).

\section{The Fertility Decline since $\mathbf{1 9 7 0}$ and the Role of Fertility Policy in that Decline}

The fertility decline in the PRC looks quite similar to the decline in other East Asian populations, although it began slightly later in the PRC. In the Republic of Korea and Taipei,China, the TFR fell to 1.0 and possibly lower with no strong administration policy. In Japan, the rate fell below 1.3 in 2003-2005. All these countries experienced rapid economic and social development.

In the PRC, government policy affected the decline in fertility since 1970, particularly the Later, Longer, Fewer Policy and the One Child Policy of the 1980s. The Later, Longer, Fewer Policy was introduced in 1971, when family planning leading groups were established in each province to implement it. Three recent studies, all using a causal analysis approach, analyze the effects of the Later, Longer, Fewer Policy. Chen and Huang (2018) use differences in timing of the formation of family planning leading groups in each province to identify their effect on fertility. They conclude that the policy implementation explains a decline of 1.46 births per woman out of a total decline of 3.00 births from 5.72 in 1969 to 2.72 births per woman (TFR) in 1978. Babiarz et al. (2018) examine differences in the timing of the policy's introduction by province and find that the Later, Longer, Fewer Policy explains a decline of about 0.90 births out of a decline of 3.25 in the TFR over a slightly different time period.

Meanwhile, Chen and Fang (2018) find the policy reduced the TFR by 0.85 , which is highly consistent with Babiarz et al. (2018). Both these studies find that once the Later, Longer, Fewer Policy is taken into account, the One Child Policy has only small and statistically insignificant effects. Both studies also agree that the Later, Longer, Fewer Policy and the decline in fertility in the 1970s were much more important than the One Child Policy and the fertility decline of the 1980s. They differ, however, on the effects the Later, Longer, Fewer Policy had on the sex ratio of births. We can conclude from these careful studies that this policy led to significant and substantial reductions in fertility. Nevertheless, it was probably not the main reason for the rapid decline in the 1970s, which might rather have been due to other social, demographic, and economic changes. 
Aside from direct fertility policy, the rapid economic and social development in the PRC in recent decades has also influenced fertility. One important dimension of development is the marked decline in mortality since 1950 . In that year, $20.5 \%$ of children died before age 5 . By 1970 this had fallen to $10.0 \%$, to $5.0 \%$ in 1990, and to just $1.4 \%$ in 2010 (UN 2017). Over the same period, life expectancy rose from 43.8 years in 1950 to 61.7 (1970), 69.7 (1990), and 75.7 (2010). There are both biological and behavioral links between high mortality and high fertility.

Another important dimension of development has been the sharp rise in the educational attainment of boys and girls. It is worth examining the relation of this to fertility in more detail because rising educational attainment is likely to affect future fertility in the PRC. The Wittgenstein Centre does periodic projections of population by educational attainment (see Figure 4 panel $b$ for the center's latest projections). Figure 4 indicates that the average grade attainment for women ages 20-39 in 2015 was 7.9 years, and that this will steadily increase to 13.4 years by 2060 . These projections can be used to assess the effect of future increases in educational attainment on fertility. Recent literature has analyzed fertility in relation to education using statistical models (Lan and Kuang 2016, Piotrowski and Tong 2016). However, because the large increase in higher education is a very recent development, it may be too early to draw conclusions about its effect on future fertility trends. For this paper, a more straightforward calculation can be based on the 2010 census as reported by Jiang et al. (2017). Panel $b$ of Figure 4 shows the estimates of completed fertility for women with different levels of education. Women with postgraduate education have a level of 1.1 compared with 1.9 for women with no education. If the categories used for the data in panels $a$ and $b$ of Figure 4 are adjusted to match, and assuming that the patterns in the 2010 census persist, the changing level of education from 2015 to 2060 will reduce completed fertility by about 0.3 births per woman. Of course, other aspects of economic development are also relevant to future fertility.

Figure 4: Projections of Women's Educational Attainment and Its Relation to Their Fertility
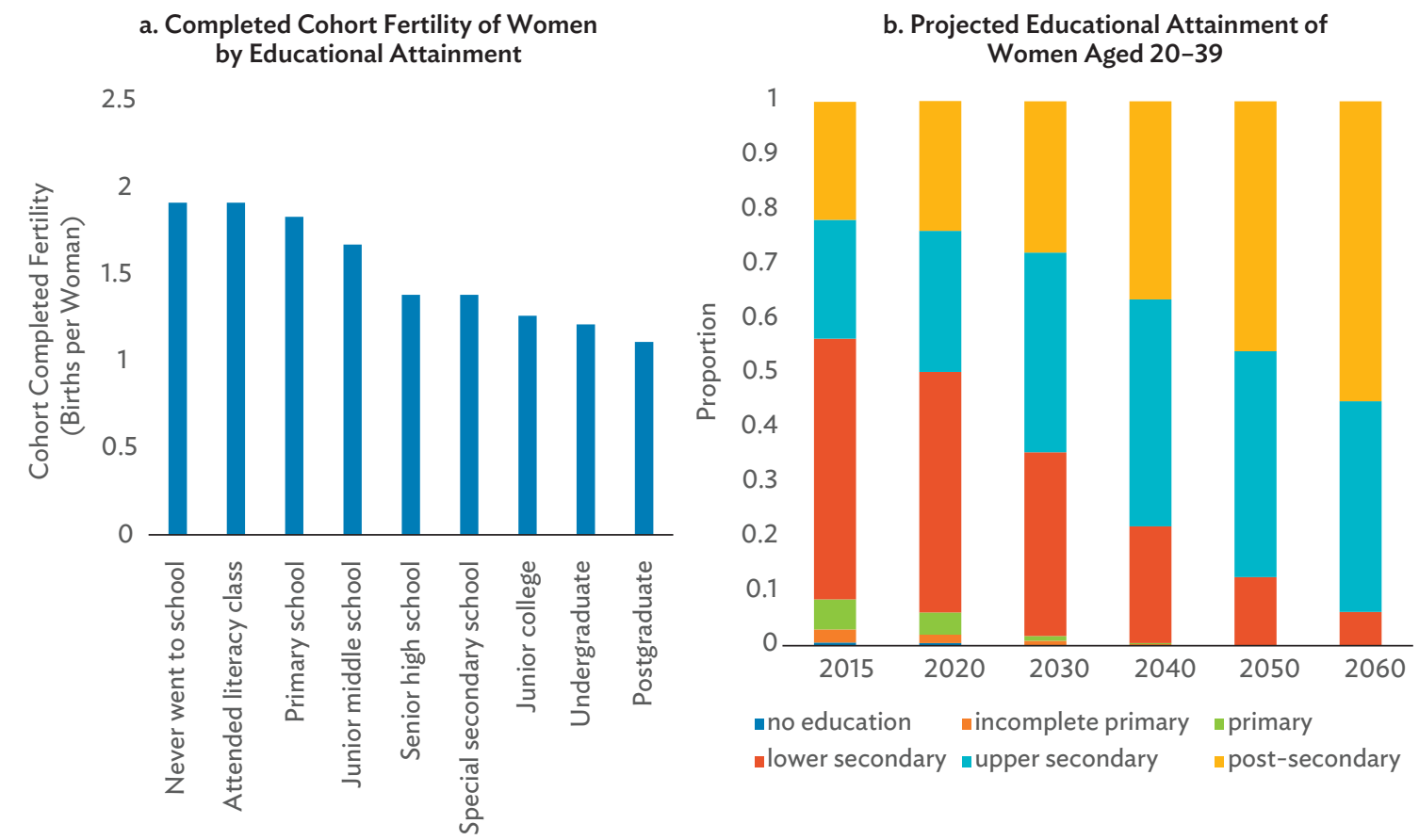

Sources: Panel a is constructed from data in Jiang et al. (2017); panel b is constructed from Wittgenstein Centre educational projections in European Commission (2018). 


\section{Is Population Aging about Chronological Age or Physiological Age and Functional Abilities?}

The conventional chronological approach defines a person as "old" after age 65 or after some other fixed age is reached. The use of specific ages of this sort often defines eligibility for government pensions, health care, long-term care, and other programs for the elderly. In this case projections of population aging defined in terms of fixed ages can be useful for projecting program costs and assessing the longterm fiscal stability of government programs. But the conviction is growing among gerontologists and others studying population aging that old age should instead be defined in relation to health and vitality, which gradually diminish with age and eventually fall below certain thresholds. The thresholds can then be used to define individual or population aging. Since direct measures of health and functional status are not always available, remaining years of life is sometimes used as a proxy for health. Consistent with this idea, it has been found that in the US, health care costs begin to rise 10 years before death (Lee and Miller 2002). Sometimes it is suggested that health and vigor begin to decline 15 years before death. Although identifying individuals who are within 15 years of death is clearly not possible prospectively, it is possible to calculate from life tables the proportion of people at each age that will die within 15 years. This proportion can then be used as an indication of functional aging. A simpler alternative is to find the age at which remaining life expectancy is 15 years, and then calculate the population at or above this age.

Two researchers, Warren Sanderson and Sergei Scherbov, have led the way in developing measures of aging based on these ideas. They report different versions of the OADR for 10 countries, projected from 2005-2010 to 2045-2050 (Sanderson and Scherbov 2010). For the average of the 10 countries, the standard demographic OADR rose from 0.28 to 0.53 , indicating a near doubling of aging. For the measure based on activities of daily living ( $A D L$ ), including projected $A D L$ trends, the equivalent measure rose only very slightly, from 0.11 to 0.12 , rather than doubling. The message from this analysis is that an increase in the OADR does not necessarily mean an increase in the relative size of the functionally dependent population. Older people nowadays, at least in the 10 countries, are better able to care for themselves and more able to continue working than would be suggested by the simple chronological measure of aging expressed by the standard demographic OADR.

For the PRC, Sanderson, Scherbov and Gerland (2017) calculated that in 2013 remaining life expectancy was 15 years at age 66, and that according to UN projections it would be 15 years at 70 by 2040 and at 73 by 2060 . So by this measure, the threshold for becoming "old" would be 7 years later in the PRC in 2060 than in 2013. They report that while the proportion of the PRC population above age 65 would triple between 2013 and 2060, the proportion with remaining life expectancy less than 15 would only double. There are similar differences for the other alternative measures in Sanderson, Gerland, and Scherbov (2017) of aging in the PRC.

\section{E. Trends in Health and Disability of the Older Population}

In the West, it is often said that 70 is the new 60, meaning that a 70-year old today is as healthy, vital, and able to work as a 60-year-old was in the past. Is this true for the PRC? The question is important for two reasons. First, if the elderly are much healthier than in the past, then they could also work longer and need not retire at 55,60 , or even 65 . They might instead work until 70 or later, greatly reducing the number of retirees and the cost of supporting them. The second reason is that a healthier older population can take better care for itself, resulting in lower long-term care costs, both for the government and for families.

For these reasons, it is essential to identify trends in the health, functional status, and disability of the elderly in the PRC in relation to the economic and social costs of population aging. Fortunately, several studies that draw on different data sources examine this. One of these is the Chinese Longitudinal Healthy Longevity Survey, used in Zeng et al. (2017) and Zeng (2019), which was designed to answer this kind of question. The study focuses on the oldest old, or those above age 80 , which makes it less relevant 
for labor supply questions; while in Zeng (2019), none of the respondents were born after 1928. Both studies compare the health status of people in age groups 80-89, 90-99, and 100-104 in 1998 andcross-sectionally for the same age groups-in 2008. Consistent with Zeng (2019), Zeng et al. (2017) found that "disability according to activities of daily living had significantly reduced annually between $0.8 \%$ and $2.8 \%$. However, cognitive impairment in the later cohorts increased annually between $0.7 \%$ and $2.2 \%$ and objective physical performance capacity (standing up from a chair, picking up a book from the floor, and turning around 360 degrees) decreased annually between $0.4 \%$ and $3.8 \%$." Both studies also found that while women had lower mortality, their health status was worse-and this tells a mixed story. The ADL measure improved considerably, indicating that these old people were better able to carry out the ordinary activities of life without assistance in 2008 than in 1998.

The ADL performance depends not only on the physical functioning of the old but also on the physical environment and presence of assistive devices. The measures of objective physical performance capacity and cognitive measures deteriorated over the comparison period (1998 to 2008) in Zeng et al. (2017). Why then would one set of measures improve and the other worsen? The authors suggest that reductions in disability of the elderly were due to environmental improvements rather than improved physical functioning. The reason why physical functioning and cognition worsened seems to be because the later-born cohorts had worse education and a worse childhood environment than those in the earlierborn cohorts. Improved medical treatment and lower mortality for the later-born cohorts may also have meant that some survived with impaired health. Although this appears to be a discouraging finding, since physical and cognitive disabilities are becoming more prevalent at each old age, the future elderly in the PRC are expected to have rising educational attainment and improved childhood nutritional and health conditions (Lei et al. 2014 document the relation of education to disability). Liang et al. (2015) also report a rapid decline in ADL prevalence among the elderly in the PRC in their study covering 1997 to 2006. They found that ADL prevalence rates declined the most for the oldest old (ages 80 and overthe ones covered by Zeng et al. 2017), but they also declined for those over 60 . The study says this suggests that national care costs for the elderly may be less than when projected on the basis of current age-specific prevalence rates. This also has implications for the ability of the elderly to continue to work.

The China Health and Retirement Longitudinal Study (CHARLS), conducted every 2 years on a sample of the population ages 45 and over, is useful for monitoring and analyzing many aspects of aging as time passes, as do similar surveys in the United States and Europe (Health and Retirement Survey, and Survey of Health, Ageing and Retirement in Europe, SHARE), and in some emerging economies. The age-specific measures of disability prevalence in the PRC for the 2011, 2013, 2015, and 2018 wavesmeasured by ADLs, IADLs (instrumental activities of daily living), and their sum-show virtually no change from wave to wave, except perhaps declines in disability for those ages 80 and over. ${ }^{4}$

Although these important studies find mixed results, it is expected that rising educational attainment and better childhood conditions will lead to declining disability in the future. The China Health and Retirement Longitudinal Study will be valuable for tracking future levels and trends in disability, and assessing the ability of older people to supply labor.

\section{F. Estimating Change in the Potential Workforce as the Population Ages}

This section describes a method that could be used in future work to estimate the proportion of the PRC's adult population (ages 20-70) that will potentially be able to work in the coming decades, set against the backdrop of population aging. Over the coming decades, the population will age; it will perhaps shift further from rural to urban areas; it will become increasingly educated; and its sex composition will change. The effect of these changes on the potential workforce can be estimated by

$4 \quad$ The data was kindly provided by lead survey investigator, John Strauss. 
using an appropriate survey, probably the China Health and Retirement Longitudinal Study (CHARLS). For making this estimate, an age is chosen at which most adults who are capable of working are in fact working - a typical age range would be 45-50. Then, using individual-level survey data, regress the workforce participation on health and disability status, educational status, and rural-urban residence (this choice of variables is illustrative). The estimated coefficients can then be applied to the projected future population and its projected characteristics (education, health status, urban or rural residence) to find the maximum available workforce at each age and sex, and then overall.

When an analysis of this sort was done for the United States, as reported in National Academy of Sciences (2012), the result was that in $201090 \%$ of the population ages $20-70$ was capable of work, and that this proportion was virtually unchanged as projected to 2050 . There were downward pressures on the proportion capable of work due to population aging, extensive immigration, rising obesity and other changes, but these were offset by the beneficial influence of rising educational attainment. In a similar way, rising educational attainment in the PRC could well offset some of the decline in functional status in the aggregate adult population that would otherwise occur due to population aging.

\section{ECONOMIC CONSEQUENCES OF POPULATION AGING}

\section{A. Age Patterns of Labor Income and Consumption}

The population age distribution and its changes have economic consequences because economic activity varies across the economic life cycle. A good starting point for considering these economic consequences, then, is to examine the way that economic activity varies by age. The large international National Transfer Accounts project (NTA), which has research teams in more than 55 countries, including the PRC, provides estimates of labor income and consumption by age, as well as many other measures. ${ }^{5}$ In the NTA, labor income includes wages, salaries, and fringe benefits for employees, as well as twothirds of self-employment income (the rest is imputed to assets, such as farms or shops). Consumption includes private household consumption and public transfers of goods and services at each age, such as public education and health care, and housing, energy, and food transfers. Cash transfers are not included because they can be used to pay for consumption, but are not themselves consumption. ${ }^{6}$

Panel a of Figure 5 shows NTA estimates of labor income by age for 2002, 2007, 2009, and 2014. It is clear that labor income has risen strongly over time, and that those younger than 20 and older than 64 earn income, although not much. Labor income also varies dramatically within the 20-64 age range, and the shape of the curve has changed considerably over the 12-year period. In 2002 the age shape of labor earnings is very symmetric, peaking at age 41. From then to 2014, the curve leans increasingly to the left, as young people with rising amounts of education increasingly work in urban areas, and the peak shifts from age 41 to 30. This distinctive age pattern of labor income reflects the dynamic growth of the PRC's economy, and is unusual among the other countries covered by the NTA. In most of them, the laborincome curve peaks in the late 40s, and considerably later than it does even in the 2002 curve in the PRC (Lee and Mason et al. 2011). The PRC's age schedule of labor income is expected to change again when the increase in educational attainment and productivity slows, at which point it may gradually revert toward the shape of 2002 or have an even later peak.

5 The PRC NTA is led by Ling Li, professor of Economics at the National School of Development and the China Center for Economic Research at Peking University. The following discussion draws extensively on the results of studies by several members of this research team, including Wang Feng, Yong Cai, and Shen Ke.

6 These and many other aspects of the NTA's methods and conventions are described in detail in UN (2013). 


\section{Figure 5: National Transfer Accounts Age Profiles for Labor Income and Consumption, 2002-2014}
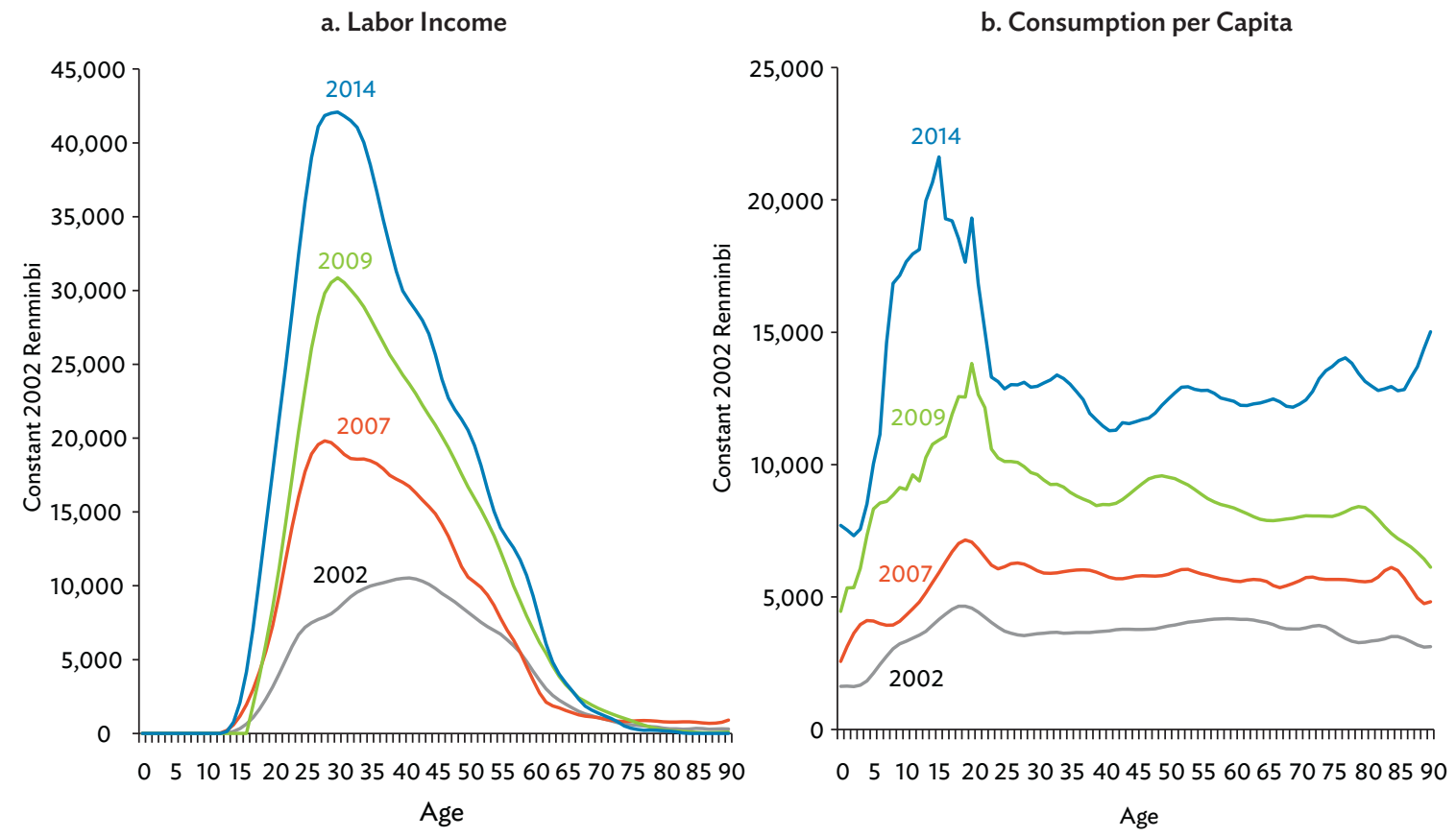

Source: Shen, Wang, and Cai (2018).

Panel $b$ of Figure 5 shows estimates of consumption by age in the PRC for the same years. There are two very striking features. The first is the rapid increase of consumption by those aged $5-25$, reflecting increasing public and private investment in education. ${ }^{7}$ The second is that despite the concentration of labor income at younger ages, and the exceptionally low labor income above age 65, consumption in each of the 4 years is very flat across adult ages. This indicates that the elderly are, at least on average, consuming about the same as younger adults who have much higher labor income. Apparently the oldage support system is functioning well through a combination of private transfers (remittances from the young in the cities, for example); public transfers, including pensions; and assets held by the elderly, such as farms, buildings, and financial assets. The NTA data show that for those aged 65 and over in $2002,56 \%$ of the gap between consumption and labor income is filled by public transfers, $20 \%$ by family transfers, and the rest by asset income. It is possible that this smoothing of consumption across age each year on average does not hold for some population groups, such as those in rural areas or with lower education or income. The NTA plans to examine this possibility in the future.

Education is counted here as consumption, but of course it is also investment in human capital, and for some purposes it will be regarded as such. 


\section{B. Population Aging and the Support Ratio}

The economic consequences of population aging can be assessed using general equilibrium analysis of overlapping generations models and in other rather complicated ways that require many assumptions, but as a starting point it will be useful to consider the simple support ratio. This is most simply measured as the "demographic support ratio"-the ratio of people of working ages (which can be taken to be 20 through 64) to the number of consumers (the entire population). In effect, this version of the support ratio is simply the population of working age as a proportion or percentage of the total population. Panel a of Figure 6 shows how this demographic support ratio has changed in the past and is projected to change in the future based on the population projections for 1950 to 2100 in UN (2017).

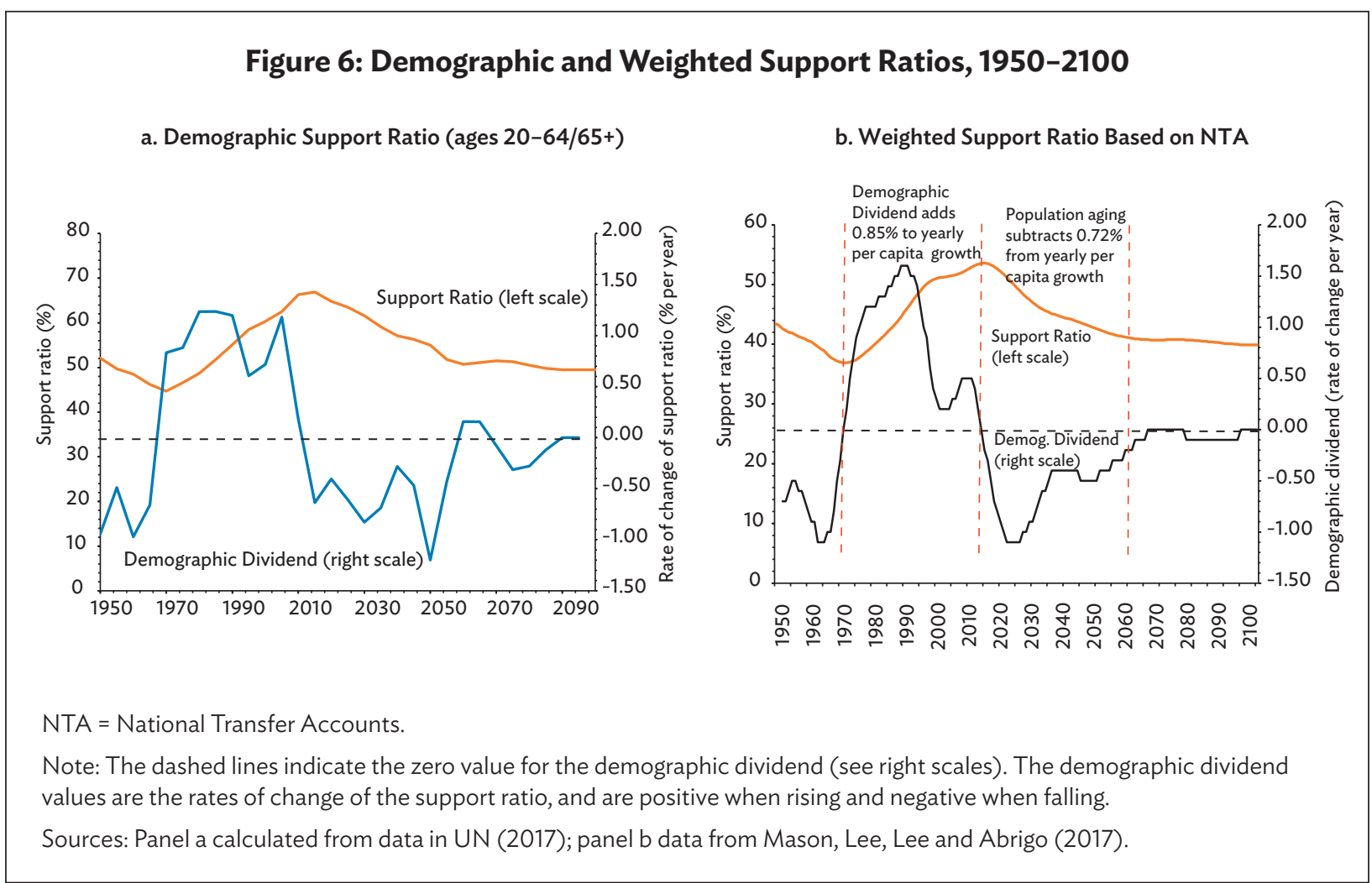

Because the UN projections shown in panel a of Figure 6 provide data only for 5 -year intervals, the exact dates of turning points are somewhat obscured. Initially, the demographic support ratio declines because mortality is declining while fertility remains high. With lower mortality, more children survive and the share of children in the population rises, enlarging the demographic support ratio's denominator, but not changing the ratio's numerator. The ratio reaches its minimum in 1970, at which point fertility begins to fall, and the share of children begins to decline. This is the beginning of the first demographic dividend, when the rising share of those of working age in the population tends to boost the rate of growth of income per capita. This share continues to rise until 2015, or over a 45-year period (although the 5-year UN data are imprecise on timing). Over that period the demographic support ratio rises by nearly $50 \%$ and its average rate of growth is $0.9 \%$. This means that other things equal, the changing age distribution of the population over these 45 years added nearly $0.9 \%$ per year to the growth rate of income per capita. This is not large compared with the phenomenal rates of growth of income per capita in recent decades, but with slower growth in labor productivity it would become much more important. As discussed later, a second demographic dividend resulted from increased investment in physical and human capital. 


\section{How Actual Age Patterns of Labor Income and Consumption Change the Support Ratio}

The demographic support ratio implicitly assumes that people at every age consume the same amount; that people at every age from 20 to 64 produce one unit of output; and that production at all other ages is zero, i.e., weighting is by zeros and ones. The reality of course is quite different, which means that the effects of changing population age distributions are also quite different.

The NTA's age profiles for a given year can be used as weights to construct "effective labor income" and "effective consumption" by multiplying the projected population age distribution with the labor income or consumption baseline age schedule, and summing. The ratio of effective labor to effective consumers is the weighted support ratio. What matters is the weighted support ratio's changes over time, not its level. Panel a of Figure 5 shows past and projected values of the demographic support ratio and the weighted support ratio in panel b for the PRC from 1950 to 2100 based on the NTA data and UN (2015) population projections.

Here, with finer grained data and the weighting just described, the demographic support ratio is at a minimum in 1971 and then begins to rise, continuing until its peak in 2013. Over that 42-year period, the ratio rises by $43 \%$, with the average rate of increase during this dividend phase at $0.85 \%$ a year. $\mathrm{A}$ maximum rate of increase of nearly $1.40 \%$ a year is reached in 1991 . These are slightly smaller effects than were calculated from the demography alone (Figure 6, panel a). At the end of the dividend phase in 2013, population aging begins to dominate and the tailwind turns into a headwind, impeding the growth rate of income per capita. Between 2013 and 2060 the support ratio drops by 29\% and the average rate of decline is $0.72 \%$ a year. This shows that whatever the growth rate of labor productivity, when it is translated into a growth rate of income per effective consumer, it will be lower by $0.72 \%$ a year on average over this period, with a maximum rate of decline of nearly $1.20 \%$ a year reached in 2025 . Contrasting the rate of change in the population-aging phase to the dividend phase shows an average difference of about $1.5 \%$ a year - a substantial amount.

\section{The Second Demographic Dividend}

The boost that the first demographic dividend gave to the PRC's economic growth lasted for 42 years. But this boost is ultimately transitory because it will be reversed by population aging. Panels $a$ and $b$ of Figure 6 show that by 2060 the demographic support ratio is back to about its initial level in 1950, or to its predividend level of 1970. A key question is whether the transitory income gains in the first dividend phase are used to increase consumption or instead invested in a way that can enhance longterm prosperity. The demographic changes that generate the first dividend also tend to raise investment in both human capital and physical capital, thereby generating a second demographic dividend that is robust and permanent (Mason and Lee 2006).

The PRC's second demographic dividend has two main components. First, as fertility declines (leading to the first demographic dividend), there is a strong tendency for human capital investment per child to rise (Mason, Lee, and Jian 2016). There are several possible explanations for this. An independent desire to invest more in each child, perhaps due to rising rates of return to an education, may lead parents to reduce their fertility in order to make such increased investment possible. Alternatively, an independent decline in fertility may make it possible for parents to invest more in each child. Or some third force, such as rising incomes, could have driven both the decline in fertility and the rise in human capital investment, as posited by the quantity-quality tradeoff fertility theory (Becker 1991). The causal direction does not matter here, and may vary from setting to setting. What matters is the association of declining fertility and rising investment in human capital per child relative to the level of labor income or GDP per capita. The NTA finds a strong negative relationship between the TFR and the sum of public and private spending 
per child on education relative to average labor income cross-nationally, a relationship that is particularly strong among Asian countries (Mason, Lee, and Jian 2016). Declining fertility is the primary driver of population aging, and it goes with increasing investment in human capital per child. As the number of new workers entering the workforce slows and perhaps declines, as in the PRC, their productivity increases due to their increased education.

The second main component of the PRC's second demographic dividend is the increasing amount of capital per worker (capital deepening) that is a natural concomitant of the demographic changes that bring population aging (e.g., lower fertility, longer life, and slower growth in the population and workforce). This can be seen from two different perspectives. First, in a standard neoclassical growth model with a fixed saving rate, the steady-state ratio of capital to labor is higher when the population growth rate is lower. Second, if the savings rate is chosen to maximize steady-state consumption, the capital-to-labor ratio will again be higher with slower population growth. In both cases it is expected that population aging will go with capital deepening and increased productivity of labor, higher wages, and lower interest rates. This is true both in a transitional phase, when workforce growth rates decline, and across steadystate growth paths.

The same conclusion can be reached by examining the PRC's changing demography and age distribution. With lower fertility and fewer children with whom to share household income, couples find saving easier and-going by lifecycle saving models - they will choose to save more. With longer life, workers will need to save a greater proportion of their income to prepare for a longer retirement, and accumulate more assets. Even if neither of these changes in saving behavior occur, and adults continue to save just as before, it will still be the elderly who have the greatest stock of assets. The increasing share of elderly in the population will then drive up the capital-to-labor ratio and boost the productivity of labor. This may, however, be less true in the PRC nowadays, where the young have higher labor earnings and may also hold a larger share of assets relative to the elderly than is the case in most countries.

The discussion in this section implicitly assumes the PRC's economy was largely closed to international markets, particularly capital markets. In an open economy, domestic wages, capital intensity, and interest rates are set on the international market. Here, the increased asset holdings that occur as the population ages can be invested in foreign markets, resulting in increased flows of asset income into the country, which raise national income (although not GDP). In either case, rising asset holdings per capita help to offset the rising old-age dependency on the working age population (Lee 2016). The reality will lie someplace between the open and closed assumptions.

Another beneficial aspect of the low fertility that brings population aging is that raising children requires major inputs of adult time - time that is typically provided by the mother, but which can also be provided by the father, grandparents, and public or private childcare services. Typically, however, declining fertility frees up women's time spent in the home and permits them to supply labor to the market in greater quantities. Indeed, a desire to take advantage of new work opportunities may be one of the reasons why women in the PRC are choosing to have fewer births.

The first demographic dividend gave the PRC economy a transitory boost from 1971 to 2013. The second demographic dividend - the contribution of demographic change to increased investment in education and physical capital - is ongoing and should be lasting.

\section{E. Is Fertility Too Low?}

Low fertility raises the share of costly elderly in the population and reduces the share of costly children. Is there a fertility level that achieves the best balance between the two? A paper in Science, authored by more than fifty NTA researchers examined this question (Lee and Mason et al. 2014). The study 
asked what level of fertility would lead to a stable population age distribution that would maximize the weighted support ratio. It took mortality as given and assumed that the baseline NTA age profiles remain fixed for labor income and consumption, and for taxes and benefits in the fiscal case. Several variations on the basic question were considered, as follows:

(i) From the point of view of the public sector, what level of fertility would maximize the fiscal support ratio (the ratio of effective tax payments to effective costs) for providing benefits? For the PRC, it was found that a TFR of 2.64-at least a full child more than the actual TFR-would maximize the fiscal support ratio. This result was close to the average for all NTA countries included in the study. The best TFR is relatively high here, reflecting the public sector's emphasis on transfers to the elderly in many countries including the PRC.

(ii) From the point of view of the whole economy rather than just the public sector, age profiles of labor income and consumption, like those in Figure 5, were used. In this case, a TFR of 2.17 would be best for the PRC, about half a child lower than the finding for just the public sector and close to replacement-level fertility. This calculation gives more weight to the costs of children, which are mainly borne by their parents rather than the public sector.

Neither of these two points take into account the need to save a portion of national income to provide capital for a growing workforce. If the aim is to maximize consumption, then the proportion saved is certainly relevant and should be taken into account. The higher is fertility, the greater is the share of output that must be saved to provide capital for the growing workforce. Lee and Mason et al. (2014) assume that savings would be adjusted to maintain a capital-to-output ratio of 3.0, equal to the average for OECD countries. When this is taken into account together with the weighted support ratio, it was found that a TFR of 1.65 would be best, which is very close to the higher end of the range of estimates of the PRC's current fertility level. From this more general economic perspective, the TFR may not be too low, at least for the long term. But if the studies that put the PRC's TFR close to 1.05 are correct, then there is reason for concern.

The analysis just described uses NTA age profiles, as observed at some recent base period. In developing countries these age profiles are certain to change in the coming years and decades, which could lead to different conclusions. It was also found that in the neighborhood of the "best" level of fertility, modest variations in fertility would not make much difference, and even differences in the TFR of plus or minus 0.5 births would have relatively small effects for overall consumption. But this finding is rather abstract. In reality, certain sectors of the economy would be heavily affected by low levels of fertility, and this would typically be true for the public sector, which is discussed in the following section.

\section{F. Population Aging and the Long-Term Fiscal Outlook for Social Welfare Spending}

Cai, Wang, and Shen (2018) use 2014 NTA data for the PRC to project the fiscal impact of population aging for social welfare on health, pensions, and education from 2015 to the end of the century, based on UN (2015) population projections. The fiscal projections involve two approaches. First, Cai, Wang, and Shen (2018) assume that the age profiles of benefits remain as estimated relative to GDP per workingage adult in 2014, that is that they rise at the same rate as productivity growth in the future. ${ }^{8}$ These projections isolate a pure effect of population aging on public welfare spending. The authors find this spending rises as a share of GDP, from $10 \%$ in 2015 to $15 \%$ in 2030, to $23 \%$ in 2050, and to about $30 \%$ in 2060; in other words, tripling under the influence of population aging. After 2060, the share of GDP is projected to remain fairly flat.

8 A chart plotting these age profiles for education, pensions, and health care is in Cai, Wang, and Shen (2018). 
The second approach assumes the PRC will gradually raise benefit levels (relative to GDP per workingage adult) to reach, by 2030, the average level in OECD countries in 2009 (again, measured relative to GDP per working-age adult in each country). Here, social welfare spending rises from 10\% of GDP in 2014 , to $20 \%$ in 2030, to $32 \%$ in 2050, and $40 \%$ in 2060, and "such a trend is, of course, unsustainable" (Cai, Wang, and Shen 2018, p.827).

The greatest responsibility for these increases lies with the pension program, which in 2015 cost about 4\% of GDP (Cai, Wang, and Shen 2018). Fang and Feng (2018) put the cost at about 5\% of GDP in 2017. Cai, Wang, and Shen (2018) find that with no increases in benefit levels its share would rise to 13.5\% of GDP by 2050 , and with increased benefit levels to $17 \% .^{9}$ It is also important to realize that as the population ages, tax revenue will increase as well as costs. An NTA-based analysis in Mason and Lee et al. (2017) indicates that between 2015 and 2065 increased tax revenue will offset $36 \%$ of the increased costs due to population aging.

Using NTA data, it is also possible to assess the impact of population aging on private, or family-based, support systems in the PRC. If we include family transfers to all ages, both to children and the elderly, the increased stress on private support systems will be about half as great, in aggregate, as will the stress on public sector support. This will arise from the difficulties that a smaller number of children will have in supporting a growing number of parents and grandparents due to rising life expectancy and low fertility.

\section{G. Policies to Raise Fertility Elsewhere that Have Worked and Not Worked}

The literature discusses three main approaches for policy to raise fertility, excluding outright coercion or denial of access to contraception or abortion. The first is financial incentives for higher fertility, either through direct payments or through tax breaks. The second approach is to make it easier for parents to combine work with raising children. The third is improving the gender balance of work in the home.

There is a substantial and growing body of research on financial incentives for higher fertility. One of the main researchers on this, Anne Gauthier, surveys the literature on the effects of policies, including "direct and indirect cash transfers for families with children, means-tested child welfare benefits, maternity and parental leave benefits, and childcare facilities and related subsidy programs" (Gauthier 2007, 324). She concludes from her survey of the literature (as of 2007) that the impact of financial incentives on fertility is typically small and it varies considerably depending on the specifics of the incentives.

In the same work, Gauthier finds that the effect of policies tends to be on the timing of births rather than on completed fertility. If some women have their children at younger ages in response to a policy, either because of direct incentives or because of fear that the policy will be changed in the future, that will temporarily raise the TFR. But it will subsequently lead to a lower TFR in the years in which the births would originally have occurred. The net effect, even if the change in timing is permanent, would be very small. ${ }^{10}$ Gauthier's summary of the literature from a decade ago still largely applies to the literature today. For example, Ouedraogo, Tosun, and Yang (2018) analyze the relation of changes in fertility to government fertility policy from 1976 to 2013 using the UN database. They conclude "there is no significant and robust relationship between the fertility rate and a country's pro-fertility or family-planning policies".

9 Further details of the PRC's pension programs are discussed in Keyong (2019).

10 If the timing of births is moved permanently to younger ages then generations will be shorter, even though the completed fertility of cohorts is unchanged. There will be two straightforward effects. First, a very small proportion of women who would otherwise have died before giving birth will now give birth before dying. Second, with the same completed cohort fertility and shorter generations, the population growth rate will be slightly higher, even in the long term. For example, if the average age of giving birth is 29 instead of age 30, and the TFR with 1.15 male births for every female birth, then the gain in the long-term (stable) population growth rate would be only about $0.03 \%$; that is, 0.0003 . The short-term gain would be larger. 
Gauthier (2007) notes that governments in Europe have tended to move away from cash benefits for children and toward policies that make it easier for families both to work and to raise children. Thévenon and Gauthier (2011) describe the variety of these policies and assess their indirect effects on fertility, which they suggest can be larger than the effects of policies that are aimed directly at raising fertility. They find that policies such as maternity leave, flexible working hours, and childcare services can have an important impact on the indirect costs of childbearing faced by couples.

In East Asian countries, including the PRC, men make a relatively small contribution to work in the home, and that this is one reason why fertility is low in the region. They conclude that low fertility in East Asia is due in part to the small role that men play in work in the household, and find that the number of children that women want to have is positively associated to the degree to which men help with housework, and negatively associated with the amount of housework that women must do. But the authors do not suggest what kinds of policy interventions might change this situation. When men in East Asia are offered paternity leave, most do not take it or take it for only a few days.

\section{POLICY RECOMMENDATIONS}

\section{A. Fertility Policy}

On the basis of the past experience in other countries, it seems that a fertility policy based on financial incentives is likely to have only a small effect. Policies will have a greater impact when they are designed to make it easier for families, particularly women, to combine raising children with working in the workforce. Policies that address the reluctance of men to help with household tasks could also be effective, but it is hard to say what these might be.

\section{B. Pension Policy}

In principle, governments can establish either prefunded or pay-as-you-go (PAYGO) pension systems. Each has advantages and disadvantages. Practically all rich industrial countries now have PAYGO systems, and although some analysts argue that these countries would be better off if they moved to prefunded systems, that would be a long, costly, and painful process fraught with danger. This is because in transition, workers must both support the current elderly, and save for their own retirements. The PRC appears to have chosen to develop PAYGO public pension systems even though individuals appear to be saving at a very high rate, accumulating funds that will ultimately be available to pay for consumption in old age. The rest of the section looks at PAYGO pension systems that the PRC could consider because they would avoid or at least soften the impact of population aging. It is strongly recommended that the parameterization of public pension programs, such as contribution rates, benefit levels, and retirement ages, be done in conjunction with careful long-term projections of the pension system's finances. These should take into account the PRC's changing demography and the changing rate of GDP growth. Because the OADR will be tripling in the coming decades, and GDP growth will be slowing, it would be a mistake to set contribution and benefit rates based on the current situation.

Any PAYGO pension system can pay a real rate of return on an individual's contributions (pension taxes) equal to the rate of growth of total wages, which under some assumptions would equal the rate 
of GDP growth." This rate of growth, in turn, equals the rate of growth of the workforce plus the rate of growth of the real wage rate, which under some assumptions equals the rate of growth of productivity. If population growth and productivity growth are both zero, then retirees would receive on average exactly what they contributed earlier. In a growing population with rising productivity, the PAYGO system would pay a positive rate of return. If the workforce is shrinking, as it is in the PRC, but productivity per worker is rising faster than the size of the workforce is declining, then the rate of return would still be positive. A PAYGO system that pays a higher rate of return than the growth rate of total wages (or of GDP) would be unsustainable. On the other hand, it would accumulate surpluses if it paid a lower rate of return than the growth rate of total wages.

The PRC should consider adopting the notional or nonfinancial defined contribution (NDC) system invented and implemented in Sweden (Holzmann and Palmer 2005). A number of countries have done this. The system adjusts automatically both to changes in life expectancy and to changes in population growth rates. In principle, this pension system is sustainable even with an aging population. It also does not distort the retirement decision of workers because the pension benefit varies in an actuarially fair way with the age at which a worker chooses to retire given their generation's life expectancy. Moreover, since workers' retirement benefits are proportional to their total payments into the system, it is likely that these payments will be viewed by workers as investments rather than as taxes.

The NDC systems mimic some key features of a defined contribution system. Each month, all workers are required by law to pay a specified percentage of their earnings into their retirement account, which is managed by the pension authority. These accounts earn a rate of return equal to the rate of growth of total wages. ${ }^{12}$ After reaching the minimum age set by the government, workers can choose when to retire. At this point, a worker's retirement account is converted into an annuity based on the worker's age at retirement and on the life table describing mortality in the year when the worker's cohort reaches some fixed age, such as 60 or 65 , and on a rate of return equal to the annual growth rate of total wages. ${ }^{13}$ This system pays the sustainable rate of return to its participants, or it would in a steady state. Given the constantly changing conditions of real-world economies there will be some imbalances, but these are eliminated by automatic adjustments.

The German PAYGO system is also worth considering as a model for the PRC (Börsch-Supan, Reil-Held, Wilke 2003; Börsch-Supan and Wilke 2004; Ludwig and Reiter 2008). Like the NDC system, there is an actuarially fair adjustment of pension benefits depending on the age at retirement, given the current life table. The level of the pension after retirement grows at the rate of growth of per capita wages. Two additional automatic adjustments are of great interest and could be of great value to the PRC. First, if the OADR rises, the pension benefit falls, helping to restore sustainability (because with a rising OADR the system would otherwise be unsustainable). Second, if the pension tax rate rises due to a rising OADR, then the benefit also falls. In this way, the pain of adjustment to population aging is shared across both workers and retirees. The same mechanisms work in reverse: if the OADR starts to fall, or the tax rate can be reduced, then benefits rise.

11 If pension tax payments are viewed by workers investments, with the later-life benefits the returns on that investment (all suitably weighted by probabilities of survival), then the discount rate that would make these two streams equal in present value is called the "implicit rate of return" for the pension system, or simply its rate of return. Many analysts have shown that in steady state, the rate of return to a PAYGO pension system (or any other transfer system for that matter) must equal the rate of population growth plus the rate of productivity growth, which is simply the rate of growth of GDP.

12 This is the way the system should be structured. For various reasons, the Swedish accounts earn a rate of return equal to the rate of growth of the wage rate rather than the total wage bill. As a consequence, the benefits paid are unsustainably high if the workforce is shrinking, and are too low if it is growing. Budget balance is then maintained by a "brake" that automatically adjusts the system if imbalances occur.

13 It would be more correct to use projections of mortality for each generation rather than using the cross-sectional life table at the fixed age. The cross-sectional lifetable is used to achieve greater transparency for participants, and to avoid the possibility that governments might manipulate and distort the mortality projections. 
Both the systems just described automatically adjust to population aging to maintain fiscal balance without requiring government intervention, and do this in a way that is fair to workers, retirees, the young, and not-yet-born generations. Auerbach and Lee $(2009,2011)$ analyze the sustainability and intergenerational fairness of these systems and of a modified version of the US system in a context of demographic and economic fluctuation and uncertainty, but do not consider a trend-like change like population aging.

\section{Education and Health Policy}

Continued investment in the education of children in the PRC will be vital given the challenges of population aging, because to some degree the decline in the number of workers can be offset by an increase in their productivity. Education is also closely associated with improved health, cognition, and functional status in old age, and so can reduce the costs of population aging, including the need for care and long-term care of the elderly, and support the option of raising labor supply at older ages. Direct investments in the health of the population, and particularly of the children, will be valuable in the face of population aging for the same reasons as for education.

\section{CONCLUSIONS}

The PRC's old-age support system, comprising family and public transfers to the elderly, and income from assets, appears to be doing a very good job of reallocating income from prosperous younger workers to the elderly. Consumption by the elderly is very similar, on average, to consumption by other adults, which shows that despite their lower earnings the elderly are receiving the support they need.

Even so, the PRC's population is aging exceptionally rapidly, posing the challenge of rising old-age dependency, which will grow worse as the country extends the reach and generosity of public programs for the elderly. Although population aging will most visibly affect the public sector, its effects will be spread across the economy, including the family transfer system. But the economy-wide effect of aging will be far less severe than one might think from focusing on the public sphere alone. There is some uncertainty about the current level of fertility in the PRC, but if the TFR is about 1.6, as the UN and some other quarters believe, then it is not clear that higher fertility would be generally beneficial for consumption levels. It would, however, certainly ease pressures on the public sector. If, on the other hand, the TFR is closer to 1.3 or even 1.0, then there would likely be economic advantages to encouraging it to rise. For policy, a close look at the failures and successes of European pronatalist policies, and policies in support of gender equity and women's participation in the workforce, would be useful.

Measures of the chronological aging of the population give an unrealistically negative picture of population aging, since rising educational attainment and incomes, and longer life, are generally accompanied by the improving health of the elderly and decreasing disability. To the extent that chronological aging of the population does not mean an increasing share of disabled, chronically ill, and frail members of the population, it could be possible to meet the economic challenges of population aging through the increased supply of labor at older ages and postponed retirement. There is good reason to expect the health of the PRC's elderly will improve in coming decades. This is because living conditions have been improving for many decades and educational attainment, a strong correlate of old age health and functional status, has also been rising. A larger supply of labor by older ages could certainly help to offset the increased costs of longer life, but it cannot realistically be expected to meet the costs of population aging alone, since population aging is largely due to low fertility rather than longer life. Raising taxes, 
curtailing public benefits, and increasing reliance on accumulated assets to support consumption in old age are all policy options that the PRC should consider.

The experience of European and other countries shows that policies to raise the pension retirement age are often, but not always, strongly opposed by workers. At this point of rapid change in the PRC's pension programs, it might be relatively easy to introduce elements of a program structure that would bring automatic adjustments in benefit levels, taxes, and retirement ages in response to future increases in life expectancy-and perhaps also to future changes in the population-age structure. Automatic adjustment mechanisms can be designed to share the costs of population aging in a fair way across generations. According to a recent review by Carone et al. (2016), since the mid-1990s half of the European Union countries have adopted either automatic balancing mechanisms, sustainability factors, or automatic linkage of retirement age to life expectancy. For example, such policies have been fairly successful in Germany and Sweden, and seem to have been more readily accepted by the people of these countries than have been the attempts at pension reform elsewhere. It is always easier if pension policy changes are made as far in advance of their implementation as possible-and the PRC should closely look at this. This might make it easier to implement the future policy adjustments that will surely be needed in light of the projected fiscal pressures discussed earlier. 


\section{REFERENCES}

A. Auerbach and R. Lee. 2011. Welfare and Generational Equity in Sustainable Unfunded Pension Systems. Journal of Public Economics. 95 (1-2). pp. 16-27.

—_. 2009. Notional Defined Contribution Pension Systems in a Stochastic Context: Design and Stability. In J. Brown, J. Liebman, and D. Wise, eds. Social Security Policy in a Changing Environment. Chicago: University of Chicago Press.

K. S. Babiarz, P. Ma, G. Miller, and S. Song. 2018. The Limits (and Harms) of Population Policy: Fertility Decline and Sex Selection in China under Mao. NBER Working Paper. No. 25130. Cambridge, MA: National Bureau of Economic Research.

G. Becker. 1991. A Treatise on the Family. Enlarged ed. Cambridge: Harvard University Press.

A. Börsch-Supan and C. B. Wilke. 2004. The German Public Pension System: How It Was, How It Will Be. NBER Working Paper. No. 10525. Cambridge: National Bureau of Economic Research.

A. Börsch-Supan, A. Reil-Held, and C. B. Wilke. 2003. How to Make a Defined Benefit System Sustainable: The "Sustainability Factor" in the German Benefit Indexation Formula. Working Paper. No. 372003. Mannheim: University of Mannheim.

Y. Cai, Wang F., and K. Shen. 2018. Fiscal Implications of Population Aging and Welfare Expansion in China. Population and Development Review. 44 (4). pp. 811-31.

P. E. Carone et al. 2016. Pension Reforms in the EU since the Early 2000s: Achievements and Challenges Ahead. European Economy Discussion Paper. No. 42. http://ec.europa.eu/economy_finance/ publications/.

L. Chen and Y. Huang. 2018. The Power of the Government: China's Family Planning Leading Group and the Fertility Decline since 1970. Global Labor Organization Discussion Paper Series. No. 204.

Y. Chen and H. Fang. 2018. The Long-Term Consequences of Having Fewer Children in Old Age: Evidence from China's “Later, Longer, Fewer" Campaign. NBER Working Paper. No. 25041. Cambridge, MA: National Bureau of Economic Research.

A. J. Coale and P. Demeny. 1982. Model Life Tables and Stable Populations. Revised ed. Princeton: Princeton University Press.

European Commission. 2018. Demographic and Human Capital Scenarios for the 21st Century: 2018 Assessment for 201 Countries. Luxembourg.

H. Fang and J. Feng. 2018. The Chinese Pension System. NBER Working Paper. No. 25088. Cambridge, MA: National Bureau of Economic Research.

A. Gauthier. 2007. The Impact of Family Policies on Fertility in Industrialized Countries: A Review of the Literature. Population Research and Policy Review. 26 (3). pp. 323-46. 
J. R. Goldstein, M. Myrskylä, and Y. H. A. Cheng. 2013. New Cohort Fertility Forecasts for the Developed World. MPIDR Working Paper. No. 2012-014. Revised April 2013. Rostock: Max Planck Institute for Demographic Research.

Z. Guo, S. Gietel-Basten, and B. Gu. 2018. The Lowest Fertility Rates in the World? Evidence from the 2015 Chinese 1\% Sample Census. China Population and Development Studies. doi.org/10.1007/ s42379-018-0012-1.

R. Holzmann and E. Palmer, eds. 2005. Non-Financial Defined Contribution (NDC) Pension Schemes: Concept, Issues, Implementation, Prospects. Washington, DC: World Bank.

Z. Jiang et al. 2017. The Fertility Level of China's Population: Analysis of Microdata from the 2010 Census. Paper presented at the 2017 meetings of the Population Association of America.

D. Keyong. 2019. Pre-Study on China's Pension Insurance During the 14th Five-Year Plan. Manila: Asian Development Bank.

M. Lan and Y. Kuang. 2016. The Impact of Women's Education, Workforce Experience, and the One Child Policy on Fertility in China: A Census Study in Guangdong, China. SpringerPlus. 5 (1). p. 1708. DOI 10.1186/s40064-016-3424-6

R. Lee. 2016. Macroeconomics, Aging and Growth. In J. Piggott and A. Woodland, eds. Handbook of the Economics of Population Ageing. Amsterdam: Elsevier.

R. Lee and A. Mason. 2011. Population Aging and the Generational Economy: A Global Perspective. Cheltenham: Edward Elgar.

R. Lee and Yi Zhou. 2017. Does Fertility or Mortality Drive Contemporary Population Aging? The Revisionist View Revisited. Population and Development Review. 43 (2). pp. 285-301.

R. Lee, A. Mason, and members of the National Transfer Accounts Project. 2014. Is Low Fertility Really a Problem? Population Aging, Dependency, and Consumption. Science. 346 (6206). pp. 229-34.

R. Lee and Timothy Miller (2002) "An Approach to Forecasting Health Expenditures, with Application to the US Medicare System," Health Services Research, v. 37, n. 5, pp. 1365-1386 (October 2002).

Lei et al. 2014. Health Outcomes and Socio-Economic Status among the Mid-Aged and Elderly in China: Evidence from the CHARLS National Baseline Data. Journal of the Economics of Ageing. 3 (C). pp. 29-43.

Y. Liang et al. 2015. Trends in Disability in Activities of Daily Living Among Chinese Older Adults, 19972006: The China Health and Nutrition Survey. Journals of Gerontology. 70 (6) pp. 739-45.

A. Ludwig and M. Reiter. 2008. Sharing Demographic Risk: Who is Afraid of the Baby Bust? Working Paper. Mannheim: Mannheim Research Institute for the Economics of Aging.

A. Mason and R. Lee. 2006. Reform and Support Systems for the Elderly in Developing Countries: Capturing the Second Demographic Dividend. Genus. LXII (2). pp. 11-35.

A. Mason, R. Lee, and J. X. Jian. 2016. Demographic Dividends, Human Capital, and Saving. Journal of the Economics of Aging. 7 (C). pp. 106-22. 
A. Mason, R. Lee, S-H Lee, and M. Abrigo. 2017. Aging and the Changing Nature of Intergenerational Flows: Policy Challenges and Responses. NTA Working Paper. No. WP16-05. National Transfer Accounts Project.

S. P. Morgan, G. Zhigang, and S. R. Hayford. 2009. China's Below-Replacement Fertility: Recent Trends and Future Prospects. Population Development Review. 35 (3). pp. 605-29.

M. Murphy (2017) "Demographic Determinants of Population Aging in Europe since 1850" POPULATION AND DEVELOPMENT REVIEW 43(2): 257-283. National Academy of Sciences. 2012. Committee on the Long-Run Macro-Economic Effects of the Aging US Population. In Aging and the Macroeconomy: Long-Term Implications of an Older Population. Washington, DC: National Academy Press.

National Bureau of Statistics of China. 2016. China Statistical Yearbook 2016. Beijing: China Statistics Press.

A. Ouedraogo, M. S. Tosun, and J. Yang. 2018. Fertility and Population Policy. Public Sector Economics. 42 (1): pp. $21-43$.

M. Piotrowski and Y. Tong. 2016. Education and Fertility Decline in China during Transitional Times: A Cohort Approach. Social Science Research. 55 (January). pp. 94-110.

S. H. Preston and A. Stokes. 2012. "Sources of population aging in more and less developed countries," Population and Development Review 38(2): 221-236.

W. C. Sanderson and S. Scherbov. 2010. Remeasuring Aging. Science. 329 (5997). pp. 1287-1288.

W. C. Sanderson, S. Scherbov, and P. Gerland. 2017 Probabilistic Population Aging. PLOS ONE. https:// doi.org/10.1371/journal.pone.0179171.

K. Shen, Wang F., and Y. Cai. 2018. A Benevolent State Against an Unjust Society? Inequalities in Public Transfers in China. Chinese Sociological Review. 45 (4). pp. 54-80.

K. Shen, Wang F., and Y. Cai. 2018. China's Age of Abundance: Tracking Changes with NTA Analyses. Paper presented at the 12th NTA Global Conference, Mexico City, Mexico, July 23-27.

O. Thévenon and A. H. Gauthier. 2011. Family Policies in Developed Countries: A "Fertility Booster" With Side-Effects. Community, Work \& Family. 14 (2). pp. 197-216.

United Nations. 2013. National Transfer Accounts Manual: Measuring and Analyzing the Generational Economy. New York.

_ 2015. World Population Prospects: The 2015 Revision. New York.

_ 2017. World Population Prospects: The 2017 Revision. New York.

—. 2019. World Population Prospects 2019. New York.

F. Wang, K. Shen, and Y. Cai. Forthcoming. Household Change and Intergenerational Transfers in China: What Lies Ahead? In Nicholas Eberstadt, eds. China's Changing Family Structure: Dimensions and Implications. Washington, DC: AEI Press. 
- 2019. Expansion of Public Transfers in China: Who Are the Beneficiaries? Journal of the Economics of Ageing. 14. 100194.

Y. Zeng. 2019. Old-Age Vitality in China and the Relevant Policy Recommendations. Manila: Asian Development Bank.

Y.Zenget al. 2017. Survival, Disabilities in Activities of Daily Living, and Physical and Cognitive Functioning among the Oldest-Old In China: A Cohort Study. Lancet. 389 (10079). pp. 619-29. 


\section{Population Aging and Its Economic Consequences for the People's Republic of China}

The population of the People's Republic of China is aging rapidly, with the old-age dependency ratio expected to more than triple by 2065. Relaxing fertility policies now may not have a large effect on fertility, and rising educational attainment may reduce future fertility by 0.3 births per woman. Parameterization of public pension programs, such as contribution rates, benefit levels, and retirement ages, should be done in conjunction with long-term projections of the pension system's finances. Pension contribution and benefit rates must consider the country's changing demography and slowing gross domestic product growth.

\section{About the Asian Development Bank}

ADB is committed to achieving a prosperous, inclusive, resilient, and sustainable Asia and the Pacific, while sustaining its efforts to eradicate extreme poverty. Established in 1966, it is owned by 68 members49 from the region. Its main instruments for helping its developing member countries are policy dialogue, loans, equity investments, guarantees, grants, and technical assistance. 